\title{
Water Consumption and Vegetative Growth Progress in Resistant and Susceptible Olive Cultivars Infected by Verticillium dahliae
}

\author{
Fahima Birem, Esteban Alcántara-Vara, Francisco Javier López-Escudero* \\ Departamento de Agronomía, Universidad de Córdoba-Campus de Excelencia Internacional Agroalimentario \\ cei A3, Edificio C4, Campus de Rabanales, Córdoba, Spain \\ Email: *ag2loesj@uco.es
}

Received 11 February 2016; accepted 17 April 2016; published 21 April 2016

Copyright (C) 2016 by authors and Scientific Research Publishing Inc.

This work is licensed under the Creative Commons Attribution International License (CC BY). http://creativecommons.org/licenses/by/4.0/

(c) (i) Open Access

\begin{abstract}
Purpose: Water consumption and vegetative growth in resistant ("Frantoio") and susceptible ("Picual") olive cultivars infected with Verticillium dahliae were assessed. Methods: Plants were inoculated with the pathogen and disease evaluated in growth chamber. Mean daily water consumption and vegetative growth were recorded during 13 weeks. Results: Water consumption significantly decreased in inoculated plants compared to non-inoculated plants during the 3rd 6th weeks after inoculation period. From the 9th week, a significantly lower consumption occurred in infected "Picual" plants compared with "Frantoio" plants. Vegetative growth was reduced in inoculated plants of both cultivars, although the reduction of the fresh weight was remarkably higher in "Picual" compared with controls due to defoliation and tissue desiccation, impeding the production of new shoots and leaves. Conversely, in "Frantoio", defoliation was significantly reduced to low levels. Conclusions: Water consumption and vegetative growth in plants of resistant ("Frantoio") and susceptible ("Picual") olive cultivars inoculated by Verticillium dahliae were consistently associated with the progress of the wilt symptoms and the level of resistance of the cultivar. Growth and water consumption reductions in "Picual" were irreversible in almost all plants, while "Frantoio" plants were able to maintain water translocation, overcome the infection and avoid vascular occlusion, and restart vegetative growth.
\end{abstract}

\section{Keywords}

Defoliating Pathotype, Disease Recovery, Olea Europaea, Verticillium Wilt of Olive

\footnotetext{
${ }^{*}$ Corresponding author.
}

How to cite this paper: Birem, F., Alcántara-Vara, E. and López-Escudero, F.J. (2016) Water Consumption and Vegetative Growth Progress in Resistant and Susceptible Olive Cultivars Infected by Verticillium dahliae. Agricultural Sciences, 7, 230-238. http://dx.doi.org/10.4236/as.2016.74023 


\section{Introduction}

Vascular wilts caused by the soil-borne pathogen Verticillium dahliae Kleb. occur in a wide range of herbaceous and woody species [1] [2]. These diseases are called tracheomycosis because the pathogen invades the xylem, where it provokes occlusion of the vascular vessels and, subsequently, a reduction in the translocation of water and inorganic nutrients [3]-[5]. One of the most destructive Verticillium wilts is Verticillium Wilt of Olive (VWO) [6]-[10]. The disease is widely spread throughout the areas in which this tree crop is economically important, such as the Mediterranean Basin countries and, especially, Spain, in which approximately 2.5 million ha are occupied by olive orchards [11]. Disease control must be approached by an integrated control strategy, in which the use of resistant cultivars plays an important role [8] [9] [12]. However, there are a number of factors related to resistance in this pathosystem that remain unknown. Some factors are related to physiological changes that occur in infected plants during pathogenesis with regard to photosynthesis, respiration and, especially, water flow interruption [13]-[16]. In affected plants, these changes cause wilt, severe defoliation, growth reduction, necrosis and, in a high percentage of cases, the death of the tree. Vascular occlusion in infected plants is caused by colonization with $V$. dahliae mycelium, but also by the accumulation of tyloses or gel plugs in infected vessels, as a defensive mechanism deployed by the plant to impede the vertical and transversal colonization of the xylem by the pathogen [1]-[5] [17]-[19]. In the case of the olive, using electron scanning microscopy, [19] visualized completely occluded vessel cells of infected plants of the susceptible cultivar "Picual" in which polysaccharide-type material accumulated. Additionally, the obstruction of the xylem lumen by the formation of tyloses and aggregates that originate from the degradation of external material of the vessel walls has been observed [19] [20]. Some of these structural defensive mechanisms occur to some degree during both compatible (susceptible) and incompatible (resistant) interactions in olive, although their success in controlling pathogen colonization appears to be associated with the levels of resistance that are ultimately exhibited by the cultivar [20]. Thus, during disease progression, knowledge of the changes in some physiological parameters would help us to better understand the resistance mechanisms that operate in plants. Therefore, the objective of this research was to assess the progress of water consumption and vegetative growth in plants of resistant and susceptible olive cultivars infected by Verticillium dahliae.

\section{Materials and Methods}

\subsection{Plant and Fungal Material}

In the experiment, nine-month-old rooted olive (Olea europaea L.) cuttings of "Picual” and "Frantoio" were used, which are highly susceptible and moderately resistant cultivars, respectively, to the defoliating isolate of Verticillium dahliae Kleb. [21] [22]. The cuttings were authenticated accessions of each cultivar, obtained from the World Olive Germplasm Bank of IFAPA, CIFA “Alameda del Obispo” (Córdoba, Spain) [23]. Plants were inoculated with a cotton-defoliating $V$. dahliae isolate, V117, from the collection of the Plant Pathology Laboratory of Departamento de Agronomía, Universidad de Córdoba. To prepare the inoculum, the pathogen was transferred from potato dextrose agar (PDA) slants, where it was maintained at $4^{\circ} \mathrm{C}$, to ten PDA plates, and the mycelium was spread uniformly over the surface of each plate. Plates were incubated for 6 days at $22^{\circ} \mathrm{C}-24^{\circ} \mathrm{C}$ [21].

\subsection{Plant Inoculation and Disease Assessment}

Plant inoculation was conducted by dipping the bare root systems of the plants in a suspension of $10^{7}$ conidia/ml for $30 \mathrm{~min}$. Then, they were transplanted to sterile soil (1:1:1, peat:sand:lime) in sterile pots and incubated in a growth chamber adjusted to $22^{\circ} \mathrm{C} \pm 2^{\circ} \mathrm{C}$. Plants remained in darkness and at $95 \% \mathrm{HR}$ for three days after inoculation to reduce losses due to the transplanting and inoculation processes. From the fourth day, plants were incubated in the growth chamber at $22^{\circ} \mathrm{C} \pm 2^{\circ} \mathrm{C}$, with the light and humidity levels adjusted to a photoperiod of 14 h (216 $\mu$ Em-2 s-1 fluorescent light) and 80\% RH. Ten replications (plants) per cultivar and treatment (inoculated and non-inoculated plants) were included.

Disease severity was evaluated on a weekly basis for 10 weeks, starting 2 weeks after inoculation. Wilt resistance was assessed on a scale from 0 to 4 based on the percentage of plant tissue affected by chlorosis, leaf and shoot necrosis or defoliation ( $0=$ healthy plant or plant without symptoms; $1=$ plant affected at $1 \%-33 \%$; $2=$ $34 \%-66 \% ; 3=67 \%-99 \%$; 4 = dead plant). The area under the disease progress curve [24] for the two cultivars 
was estimated with reference to the maximum value potentially reached over the ten-week assessment period (AUDPCP) according to this formula: AUDPCP $=[\mathrm{t} / 2 *(\mathrm{~S} 2+2 * \mathrm{~S} 3+\cdots+2 \mathrm{Si}-1+\mathrm{Si}) / 4 * \mathrm{n}] * 100$ (where $\mathrm{t}=$ interval in days between observations; $\mathrm{Si}=$ final mean severity; 4 = maximum disease rating; $\mathrm{n}=$ number of observations).

\subsection{Water Consumption}

After inoculation and during the disease assessment period, plant watering was controlled with the aim of evaluating water consumption in infected plants compared to non-inoculated control plants. Therefore, $300 \mathrm{ml}$ of water was added to each pot every three days. This water dosage per plant had been previously estimated using watering probes to be optimal for covering the water necessities of the plants with respect to the pot volume (1.5 l.) and soil density $\left(1.2 \mathrm{~g} / \mathrm{cm}^{3}\right)$ during this period. This watering schedule was substituted one day every two weeks by irrigation with $150 \mathrm{ml}$ of a Hoagland complete nutritive solution [25] plus $150 \mathrm{ml}$ of water. Pots were weighed just before and after watering at each recording date using a balance. The mean daily water consume per plant between recording dates was calculated according to the formula: (Wbi - Wai-1)/3 (where Wbi = weight of the pot at the recording date "i" before watering, Wai-1 = weight of the pot at the recording date "i-1" after watering). These values were used for building daily and accumulated water consumption progress curves.

\subsection{Vegetative Growth: Fresh and Dry Weight}

For evaluating the influence of the VWO progress on the vegetative growth of olive plants inoculated with $V$. dahliae compared with the non-inoculated controls, the tips of all shoots of each plant were marked with an indelible marker at the last node. During inoculation, while plant roots were naked and released from the soil for dipping, the fresh weight of the entire plants were recorded using a balance. At the end of experiments, thirteen weeks after inoculation, the fresh weight of new tissues grown from marked points at plant shoot tips, the entire root, and the rest of tissues of each plant were recorded separately. Thereafter, these parts of each plant were collected separately in paper envelopes and dried in an oven at $70^{\circ} \mathrm{C}$ for $48 \mathrm{~h}$, and subsequently, the dried weight of the samples was recorded.

\subsection{Analysis of Results}

An analysis of variance (ANOVA) of the AUDPCP, water consumption and fresh and dry weight values reached in the experiment for plants of "Picual" and "Frantoio" was used to determine variability between treatments. Statistical analyses were performed using the Statistix 9.0 program (Analytical Software, Tallahassee, FL, USA). Mean values were compared using the Fisher's protected LSD test at $\mathrm{P}=0.05$.

\section{Results}

\subsection{Disease Symptoms and Progress}

In the susceptible cultivar "Picual", chlorosis was very common, and earlier symptoms were exhibited by infected plants, including wilt and flaccidity of leaves and stems. Chlorosis started by the 3rd week after inoculation, affecting all the shoots in many of the plants of this treatment. However, in some of the plants, it only affected the old leaves that were attached to the main stem at the basal and medium zones. Chlorosis was accompanied in some of the plants by a progressive process of leaves rolling inwards and the dieback of shoots, reproducing the so-called "apoplexy syndrome". Nevertheless, defoliation of green leaves was the most important symptom that affected almost all of the infected "Picual" plants. In several plants, defoliation was very severe, affecting more than the $70 \%$ of the green leaves of all the shoots. In this susceptible cultivar, the onset of symptom development was observed from the 3rd to the 4th weeks after inoculation (Figure 1). Thereafter, Verticillium wilt progressed moderately between the 4 th and 7 th weeks after inoculation. From this moment, symptom expression increased dramatically, causing severe symptoms that affected up to $100 \%$ of the plants (Figure 1). At the end of the experiment, all plants were killed by the pathogen.

In contrast, although $60 \%$ of the inoculated plants of the resistant cultivar "Frantoio" were affected during the observation period, disease onset was remarkably delayed compared with "Picual", and the symptoms were very slight in all cases (Figure 1). Thus, infected plants did not exhibit leaf defoliation, and only a few plants showed 


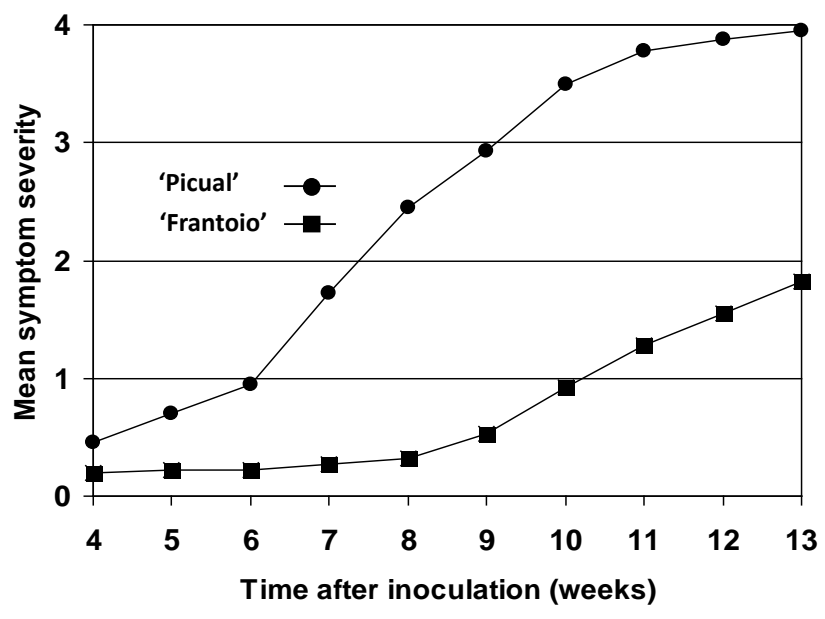

Figure 1. Disease progress based on the symptom severity of the olive cultivars "Picual” (susceptible) and "Frantoio" (resistant) after root-dip inoculation with the defoliating pathotype of Verticillium dahliae in a growth chamber. The disease was assessed for 13 weeks, beginning 2 weeks after inoculation, on a scale from 0 to 4 based on the percentage of plant tissue affected by chlorosis, leaf and shoot necrosis or defoliation $(0=$ healthy plant or plant without symptoms; 1 = plant affected by $1 \%$ to $33 \% ; 2=34 \%$ to $66 \% ; 3=67 \%$ to $99 \% ; 4=$ dead plant).

very slight chlorosis. Similarly, new leaves that grew on plants of this treatment during the incubation period in the controlled chamber did not show chlorosis. Ultimately, the final mean severity and AUDPCP values were significantly lower in "Frantoio" than in "Picual”, reaching 1.1\% and 10.5\%, respectively (Figure 1). Indeed, the pathogen did not kill any of the plants. During the experiment, plants of this cultivar exhibited recovery from the disease [26], expressed as a reduction in the disease symptoms. This phenomenon occurred in plants that had exhibited moderate disease symptoms and produced new green tissues from the 10th week after inoculation. Non-inoculated control plants of both cultivars did not exhibit the mentioned symptoms and yielded new shoots and twigs from the 4th-5th weeks after inoculation normally.

\subsection{Water Consumption}

Daily water consumption varied over the period of disease assessment between inoculated and non-inoculated plants, and it depended on the resistance of the cultivar (Figure 2). During the first 4 weeks after inoculation, water consumption increased from 50 to 80 - $85 \mathrm{ml}$ per plant per day. From the 4th to the 9th weeks, alternating increases and decreases were observed, and thereafter, this parameter stabilized. Water consumption was significantly lower in inoculated plants of both cultivars than in non-inoculated control plants from the 3rd to the 6th weeks after inoculation. These differences were maintained from the 9th week after inoculation to the end of the experiment (Figure 2). Additionally, in this period, differences were detected between inoculated plants of the two cultivars. Thus, significantly lower water consumption was recorded in infected "Picual" plants than in "Frantoio" plants (Figure 2). The accumulated water consumption showed a similar trend (Table 1). From the 7th week after inoculation, there were significant differences between the water consumption of inoculated and non-inoculated plants. Similarly, from the 9th week after inoculation, the accumulated water consumption of inoculated "Picual” plants remained statistically lower than that of inoculated "Frantoio” plants (Table 1).

\subsection{Vegetative Growth: Fresh and Dry Weight}

Vegetative growth was reduced in inoculated plants of both cultivars due to infections caused by V. dahliae, although the reduction was remarkably higher in "Picual" than in "Frantoio" (Table 2 and Table 3). The initial fresh weight was similar for both cultivars (Table 2). Final values of this parameter were significantly lower in inoculated plants of "Picual" than in the rest of the treatments. Thus, the reduction of the fresh weight of inoculated 


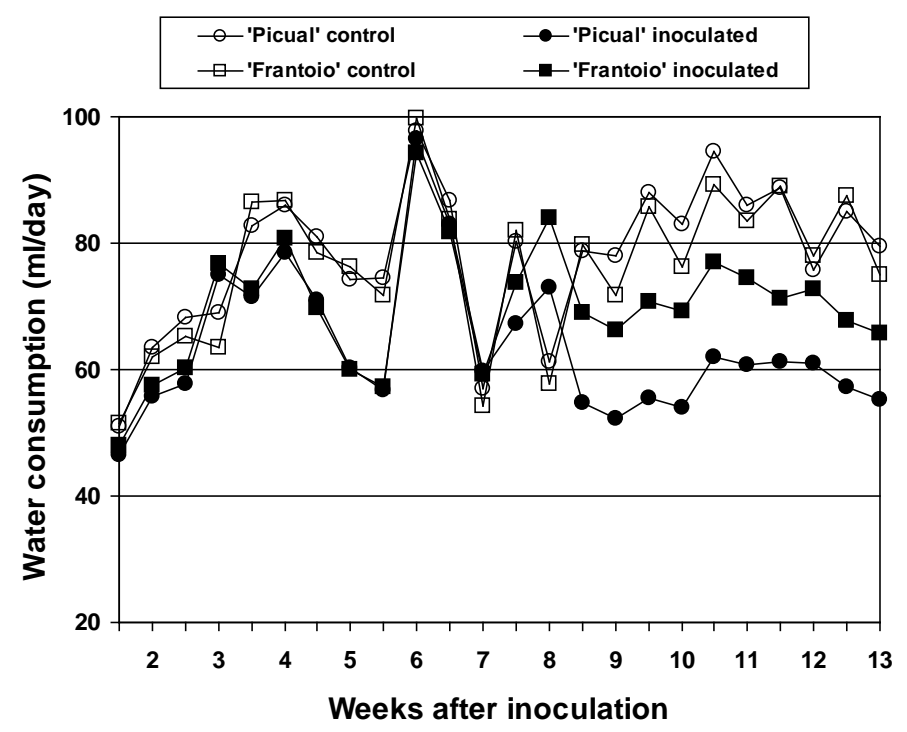

Figure 2. Daily water consumption of plants of the olive cultivars "Picual" (susceptible) and "Frantoio" (resistant) after root-dip inoculation with the defoliating pathotype of Verticillium dahliae in a growth chamber.

Table 1. Accumulated water consumption in different weeks after inoculation of olive plants with a defoliating isolate of Verticillium dahliae in controlled conditions ${ }^{\mathrm{a}}$.

\begin{tabular}{cccc}
\hline & & Accumulated water consumed $(\mathrm{ml})$ in the period & \\
\hline Cultivar & 0 to 7 wai & 7 to13 wai & 0 to13 wai \\
"Picual” C & $2220.1 \mathrm{a}$ & $2473.3 \mathrm{a}$ & $4693.4 \mathrm{a}$ \\
"Frantoio" C & $2199.4 \mathrm{a}$ & $2424.4 \mathrm{a}$ & $4623.8 \mathrm{a}$ \\
"Picual” I & $2013.0 \mathrm{~b}$ & $1786.5 \mathrm{c}$ & $3799.5 \mathrm{c}$ \\
"Frantoio" I & $2031.1 \mathrm{~b}$ & $2151.9 \mathrm{~b}$ & $4183.0 \mathrm{~b}$ \\
\hline
\end{tabular}

${ }^{\mathrm{a}} \mathrm{C}=$ non-inoculated control; $\mathrm{I}$ = inoculated plants; wai = weeks after inoculation. Values in columns followed by the same letter were not significantly different at $\mathrm{P}=0.05$ according to Fisher's protected LSD test.

Table 2. Fresh weight of tissues of olive plants inoculated with a defoliating isolate of Verticillium dahliae in controlled conditions ${ }^{\mathrm{a}}$.

\begin{tabular}{cccccc}
\hline & & \multicolumn{3}{c}{ Fresh weight (g) } \\
\hline Cultivar & $\begin{array}{c}\text { Before inoculation: } \\
\text { Complete plants }\end{array}$ & $\begin{array}{c}\text { Complete } \\
\text { plants }\end{array}$ & Roots & $\begin{array}{c}\text { Neeks after inoculation } \\
\text { Nreen leaves and } \\
\text { shoots }\end{array}$ & $\begin{array}{c}\text { Plants without roots and } \\
\text { new green tissues }\end{array}$ \\
"Picual" C & $104.7 \mathrm{a}$ & $111.8 \mathrm{a}$ & $46.2 \mathrm{a}$ & $11.7 \mathrm{a}$ & $52.8 \mathrm{a}$ \\
"Frantoio" C & $85.2 \mathrm{a}$ & $128.4 \mathrm{a}$ & $51.8 \mathrm{a}$ & $13.6 \mathrm{a}$ & $60.5 \mathrm{a}$ \\
"Picual" I & $83.3 \mathrm{a}$ & $44.4 \mathrm{~b}$ & $23.2 \mathrm{~b}$ & $0.0 \mathrm{~b}$ & $20.2 \mathrm{~b}$ \\
"Frantoio" I & $86.5 \mathrm{a}$ & $100.2 \mathrm{a}$ & $43.0 \mathrm{a}$ & $2.2 \mathrm{~b}$ & $53.9 \mathrm{a}$ \\
\hline
\end{tabular}

${ }^{\mathrm{a}} \mathrm{C}=$ non-inoculated control; $\mathrm{I}=$ inoculated plants. Values in columns followed by the same letter were not significantly different at $\mathrm{P}=0.05$ according to Fisher's protected LSD test. 'beaves and tissues produced after inoculations during the incubation period in the controlled chamber.

“Picual” plants accounted for 60.3\% compared with non-inoculated plants. This reduction occurred in all the examined parts of the plants. Therefore, the root growth of infected plants of this susceptible cultivar was half (23.2 g) of the value recorded in control plants (46.2 g) (Table 2). Moreover, disease impeded the production of new shoots and leaves. Conversely, the final fresh weight of new green tissues produced by shoots of 
Table 3. Dry weight of tissues of olive plants after 13 weeks post-inoculation with a defoliating isolate of Verticillium dahliae under controlled conditions ${ }^{\mathrm{a}}$.

\begin{tabular}{ccccc}
\hline & \multicolumn{3}{c}{ Dry weight (g) } \\
\hline Cultivar & Complete plants & Roots & New green leaves and shoots ${ }^{\mathrm{b}}$ & $\begin{array}{c}\text { Plants without roots and new } \\
\text { green tissues }\end{array}$ \\
"Picual” C & $47.3 \mathrm{a}$ & $13.8 \mathrm{a}$ & $5.0 \mathrm{a}$ & $28.5 \mathrm{a}$ \\
"Frantoio" C & $51.4 \mathrm{a}$ & $14.7 \mathrm{a}$ & $5.7 \mathrm{a}$ & $31.0 \mathrm{a}$ \\
"Picual” I & $20.7 \mathrm{~b}$ & $6.4 \mathrm{~b}$ & $0.0 \mathrm{~b}$ & $24.3 \mathrm{~b}$ \\
"Frantoio" I & $39.8 \mathrm{a}$ & $11.4 \mathrm{a}$ & $0.9 \mathrm{~b}$ & $27.5 \mathrm{a}$ \\
\hline
\end{tabular}

${ }^{\mathrm{a}} \mathrm{C}=$ non-inoculated control; $\mathrm{I}=$ inoculated plants. Values in columns followed by the same letter were not significantly different at $\mathrm{P}=0.05$ according to Fisher's protected LSD test. 'Leaves and tissues produced after inoculation during the incubation period in the controlled chamber.

non-inoculated plants reached $11.7 \mathrm{~g}$. Finally, the fresh weight of the rest of the plant tissues (without the roots and new green tissues produced during the incubation period in the chamber) was $61.7 \%$ lower than in control plants due to defoliation and leaf and shoot desiccation (Table 2). In contrast, the fresh weight reduction in inoculated "Frantoio" plants was low (21.9\%). Analysis of variance revealed that this difference was primarily due to the reduction in the production of new shoots and leaves in inoculated plants, for which the fresh weight was 83.3\% lower than that of non-infected plants (Table 2). The reduction of the fresh weight of roots and the rest of aerial tissues was low and did not differ between inoculated and non-inoculated plants of this resistant cultivar. Non-inoculated control plants of both cultivars grew normally during the assessment period, yielding similar amounts of new green shoots and leaves that weighed a mean of $12.6 \mathrm{~g}$ (Table 2). Analogous results were observed when the dry weight of the plants was investigated (Table 3). Thus, the reduction in the dry weight of complete inoculated plants compared with that of the corresponding non-infected control plants accounted for $56.2 \%$ and 22.5\% for "Picual" and "Frantoio", respectively (Table 3).

\section{Discussion}

In the olive and other hosts of the pathogen, several structural (callose and lignin material deposition; tylose or gel plug formation in infected vessels) and/or biochemical (i.e, phytoalexin and toxic substance production) mechanisms are deployed by the plants before and/or after infection to impede colonization [1]-[5] [17]-[20] [27]. Subsequently, several physiological alterations may occur in infected plants that influence, among other things, photosynthesis, nutrient translocation, water transport, and/or respiration [13] [14] [16].

AUDPC (area under disease progress curve) values recorded in this study for "Picual” (61.6\%) and "Frantoio" (10.5\%) plants after inoculation with a defoliating isolate of $V$. dahliae by a root dip were very similar to those reported in several research works related to programs responsible for assessing the VWO resistance of olive cultivars [21] [22] [28]. Thus, in these studies, the mean values of AUDPC accounted for $57.5 \%$ and $17.4 \%$ of the susceptible and resistant olive genotypes, respectively.

Daily water consumption increased until 4 weeks after inoculation, likely due to the recovery of plants from the stress caused by the root baring and plant transplanting during the inoculation process. It is likely that the initial colonization of the plant by the pathogen does not induce water flow disruption. Regardless of the cultivar resistance level, between the 3rd and the 6th weeks after inoculation, infected plants consumed a lower amount of water compared with the non-inoculated control plants (Figure 2, Table 1). This fact may be associated with the tyloses and gums that accumulate in xylem vessels. This resistance mechanism seems to be deployed in a similar manner in susceptible and resistant olive plants when they are infected by $V$. dahliae [20]. Therefore, the heavy colonization of olive tissues by the pathogen clearly precedes disease symptoms development, as observed by both microscopy [20] [29] and molecular studies [30]. Nevertheless, in the non-compatible reaction (the "Frantoio" resistant cultivar), vessel plugging to restrict the colonization of the xylem by the pathogen was successfully implemented by the plant on time and in the right places. This finding corroborates previous researches supported by anatomical observations by [20], and explains well the physiological consequences for vascular flow interruption in compatible and non-compatible interactions. From the 7th week after inoculation until the end of the experiment, inoculated plants consumed less water than non-inoculated plants, and water consumption was significantly higher in susceptible "Picual" than in resistant "Frantoio" plants (Figure 2, Table 1). It is likely that these differences were due to differences in the inhibition of water flow in the vascular 
system and in stomata. Additionally, the loss of green leaves and the lack or the reduction in the production of new shoots by affected plants also contributed to diminished transpiration and, subsequently, water consumption.

The fresh and dry weights of plants were the major parameters used to assess the differential vegetative growth in olive cultivars with different levels of resistance to $V$. dahliae (Table 2 and Table 3). Infections caused by the defoliating isolate of the pathogen reduced the growth of inoculated plants of both genotypes, although the reduction was significantly higher in "Picual" than in "Frantoio". This is the first qualitative information available in the scientific literature regarding the interference in the vegetative growth of the olive caused by infections of $V$. dahliae, especially concerning genotypes with different resistance levels. Several scientific studies have reported similar results with respect to the reduction in the vegetative growth of various herbaceous hosts due to vascular wilts caused by Verticillium sp. or Fusarium sp. In almost all cases, one of these pathogens significantly reduced plant growth, as can be seen in studies on tomato or eggplants infected by V. dahliae by [31]. Furthermore, in some of these studies, growth reduction was related to the resistance level of the evaluated variety of the species, such as sunflower [16] or pepper [32]. In both resistant and susceptible olive cultivars, the vegetative growth of the plants stopped after infection by the pathogen. Nevertheless, plants of "Picual" were more extensively colonized, provoking severe symptoms that led to the plant losing green tissues and to the death of shoots and buds. Meanwhile, in "Frantoio", plants were able to reduce pathogen colonization and significantly reduce defoliation and, consequently, maintain green tissues. Temporary or definitive reductions in the vegetative growth of infected olive plants due to VWO, in which severe symptoms lead to plant death, have been observed in controlled and field conditions and are correlated with the natural recovery capability of the plant. Thus, [26] demonstrated that plants of the resistant genotypes "Frantoio" and "Empeltre” were able to overcome infections and to restart vegetative growth between 7 to 9 weeks after inoculation with the defoliating pathotype of $V$. dahliae in controlled conditions (growth chamber).

Moreover, in field conditions, a reduction of the normal seasonal growth of olive trees has been observed upon infection by this pathogen. Thereafter, particularly when the disease symptoms of the plants are moderate, and depending on the duration of a favorable environment for disease progress, the pathogen virulence in soil, and the level of the resistance of the cultivar, natural disease recovery frequently occurs [12]. Indeed, this natural phenomenon has been repeatedly reported in a number of woody hosts of $V$. dahliae and other vascular pathogens, which include the olive [1] [12] [26] [33]. In this sense, present results clearly clarified how the genetic resistance in "Frantoio" is finally expressed as mechanism that allow infected plants to maintain water translocation and recover from the disease producing new vegetative growth.

Thus, in the susceptible cultivar "Picual", growth reduction seemed to be irreversible in almost all plants, due to the severe progress of the disease symptoms, especially the defoliation of green leaves and the desiccation and necrosis of tissues. Additionally, root growth was reduced to half of that of the control treatment, and plants did not produce new shoots or leaves during the evaluated period (Table 2 and Table 3). Remarkably, in inoculated plants of this genotype, the dry weight was reduced by the disease at a lower rate than the fresh weight when compared with control plants because part of the shoots and leaves of the former had suffered desiccation and necrosis during disease progression. In contrast, the loss of tissues caused by the copious defoliation of green leaves induced by the defoliating isolate of the pathogen was likely the main factor that influenced the reduction of the fresh weight of the aerial plant tissues (Table 2 and Table 3). Conversely, plants of the resistant genotype "Frantoio" exhibited few symptoms, and they produced new shoots and leaves after 10 weeks postinoculation, which was conducive to plant recovery. These findings provide new information for the knowledge of physiological mechanisms which operate during the infection process of this vascular pathogen.

\section{Conclusion}

Many aspects related to the pathogenesis process in plants infected by Verticillium dahliae and other vascular pathogens are very complex and may produce physiological alterations influencing, among others, on the photosynthesis, nutrient translocation, water transport, and/or respiration [13] [14] [16] [34] [35]. Characterization of these interactions would be helpful for better understanding how the resistant mechanisms operate. In the present study we have demonstrated that water consumption and vegetative growth in plants of resistant ("Frantoio") and susceptible ("Picual”) olive cultivars inoculated by Verticillium dahliae are consistently associated with the progress of the wilt symptoms and the level of resistance of the cultivar. Thus, the initial colonization of 
the plant by the pathogen had not an influence on the water flow disruption. Later on, from the onset of wilt symptoms, infected plants of both cultivars consumed lower amount of water compared with non-inoculated control plants but, interestingly, in this period only the susceptible cultivar "Picual" showed symptoms. On the contrary, disease symptoms in plants of the resistant cultivar "Frantoio" significantly were delayed. This fact was likely associated to the tyloses and gums accumulation in xylem vessels, to avoid colonization by the pathogen, which was a structural mechanism deployed in infected olive regardless resistant level of the cultivar. Nevertheless, it seems that vessel plugging for restricting fungus colonization is successfully carried out by the plant on time and at relevant places, only by resistant cultivars. When the disease progressed over time, inoculated plants consumed less water than non-inoculated plants, being differences significantly higher in the susceptible than in resistant cultivar. This was most likely linked to the influence of symptom progress on the vegetative growth. Thus, in both resistant and susceptible olive cultivars, plant vegetative growth stopped after inoculation. Nevertheless, in "Picual" plants growth detention was accompanied by a heavy defoliation of green leaves, and a progressive and irreversible desiccation and necrosis of tissues. On the contrary, "Frantoio" plants were able to avoid extensive colonization and severe symptoms, which allowed plants to maintain green tissues, to restart water flow, and to recover from infections.

\section{Acknowledgements}

This research was partially supported by the Project P08-AGR-03635 of the Ministry of Agriculture and Fisheries, Government of Andalusia (Spain) and AGL 2011-30137 (Spanish Ministerio de Ciencia e Innovación, cofinanced by FEDER of the EU). We thank Dr. Luis F. Roca Castillo for his helpful review of the manuscript and Drs. Caballero and Del Río for kindly supplying plant material from the World Olive Germplasm Bank of IFAPA, CIFA “Alameda del Obispo” (Córdoba, Spain).

\section{References}

[1] Hiemstra, J.A. and Harris, D.C. (1998) A Compendium of Verticillium Wilt in Tree Species. Ponsen \& Looijen, Wageningen.

[2] Pegg, G.F. and Brady, B.L. (2002) Verticillium Wilts. Cromwell Press, Trowbridge, 552 p. http://dx.doi.org/10.1079/9780851995298.0000

[3] Beckman, C.H. (1987) The Nature of Wilt Diseases of Plant. APS Press, St. Paul.

[4] Mace, M.E., Bell, A.A. and Beckman, C.H., Eds. (1981) Fungal Wilt Diseases of Plants. Academic, New York.

[5] Yadeta, K.A. and Thomma, B.P.H.J. (2013) The Xylem as Battleground for Plant Hosts and Vascular Wilt Pathogens. Frontiers in Plant Science, 4, Article 97. http://dx.doi.org/10.3389/fpls.2013.00097

[6] Bubici, G. and Cirulli, M. (2011) Verticillium Wilt of Olives. In: Schena, L., Agosteo, G.E. and Cacciola, S.O., Eds., Olive Diseases and Disorders, Transworld Research Network, Kerala, 191-222.

[7] Jiménez-Díaz, R.M., Cirulli, M., Bubici, G., Jiménez-Gasco, M.D., Antoniou, P.P. and Tjamos, E.C. (2012) Verticillium Wilt, a Major Threat to Olive Production: Current Status and Future Prospects for Its Management. Plant Disease, 96, 304-329. http://dx.doi.org/10.1094/PDIS-06-11-0496

[8] López-Escudero, F.J. and Mercado-Blanco, J. (2011) Verticillium Wilt of Olive: A Case Study to Implement an Integrated Management Strategy to Control a Soil-Borne Pathogen. Plant and Soil, 344, 1-50. http://dx.doi.org/10.1007/s11104-010-0629-2

[9] Mercado-Blanco, J. and López-Escudero, F.J. (2012) Verticillium Wilt of Olive and Its Control: The Heat Is on. Plant and Soil, 355, 17-21. http://dx.doi.org/10.1007/s11104-011-1091-5

[10] Tsror, L. (2011) Epidemiology and Control of Verticillium Wilt on Olive. Israel Journal of Plant Sciences, 59, 59-69. http://dx.doi.org/10.1560/IJPS.59.1.59

[11] Barranco, D., Fernández-Escobar, R. and Rallo, L. (2008) El cultivo del olivo. Coed. Junta de Andalucía/Mundi-Prensa, Madrid.

[12] Trapero, C., Serrano, N., Arquero, O., Trapero, A. and López-Escudero, F.J. (2013) Field Resistance to Verticillium Wilt in Selected Olive Cultivars Grown in Two Naturally Infested Soils. Plant Disease, 97, 668-674. http://dx.doi.org/10.1094/PDIS-07-12-0654-RE

[13] Abeles, F.B., Morgan, P.W. and Saltviet, M.E. (1992) Ethylene in Plant Biology. Academic Press Limited, London.

[14] Resende, M.L.V., Flood, J., Ramsden, J.D., Rowan, M.G., Beale, M.H. and Cooper, R.M. (1996) Novel Phytoalexins 
Including Elemental Sulphur in the Resistance of Cocoa (Theobroma cacao L.) to Verticillium Wilt (Verticillium dahliae Kleb.). Physiological and Molecular Plant Pathology, 48, 347-359. http://dx.doi.org/10.1006/pmpp.1996.0028

[15] Robert, L.B., Douglas, I.R. and Thomas, D.S. (1990) Mechanism of Photosynthesis Decrease by Verticillium dahliae in Potato. Plant Physiology, 94, 1048-1055. http://dx.doi.org/10.1104/pp.94.3.1048

[16] Sadras, V.O., Quiroz, F., Echarte, L., Escande, A. and Pereyra, V.R. (2000) Effect of Verticillium dahliae on Photosynthesis, Leaf Expansion and Senescence of Field-Grown Sunflower. Annals of Botany, 86, 1007-1015. http://dx.doi.org/10.1006/anbo.2000.1267

[17] Tjamos, E.C. and Beckman, C.H. (1989) Vascular Wilt Diseases of Plants. NATO-ASI Series, Vol. 28, Springer, Berlin. http://dx.doi.org/10.1007/978-3-642-73166-2

[18] Fradin, E.F. and Thomma, B.P.H.J. (2006) Physiology and Molecular Aspects of Verticillium Wilt Diseases Caused by V. dahliae and V. albo-atrum. Molecular Plant Pathology, 7, 71-86. http://dx.doi.org/10.1111/j.1364-3703.2006.00323.x

[19] Baídez, A.G., Gómez, P., del Río, J.A. and Ortuño, A. (2007) Dysfunctionality of the Xylem in Olea europaea L. Plants Associated with the Infection Process by Verticillium dahliae Kleb. Role of Phenolic Compounds in Plant Defense Mechanism. Journal of Agricultural and Food Chemistry, 55, 3373-3377. http://dx.doi.org/10.1021/jf063166d

[20] Rodríguez-Jurado, D. (1993) Interacciones huésped-parásito en la marchitez del olivo (Olea europaea L.) inducida por Verticillium dahliae Kleb. PhD Thesis, University of Córdoba, Córdoba (in Spanish).

[21] López-Escudero, F.J., del Río, C., Caballero, J.M. and Blanco-López, M.A. (2004) Evaluation of Olive Cultivars for Resistance to Verticillium dahliae. European Journal of Plant Pathology, 110, 79-85. http://dx.doi.org/10.1023/B:EJPP.0000010150.08098.2d

[22] Martos-Moreno, C., López-Escudero, F.J. and Blanco-López, M.A. (2006) Resistance of Olive Cultivars to the Defoliating Pathotype of Verticillium dahliae. HortScience, 41, 1313-1316.

[23] Caballero, J.M. and Del Rio, C. (2008) The Olive World Germplasm Bank of Spain. Acta Horticulturae, 791, 31-38. http://dx.doi.org/10.17660/ActaHortic.2008.791.1

[24] Campbell, C.L. and Madden, L.V. (1990) Introduction to Plant Disease Epidemiology. John Wiley \& Sons, New York.

[25] Hoagland, D.R. and Arnon, D.I. (1950) The Water-Culture Method for Growing Plants without Soil. California Agricultural Experiment Station Circ. No 347.

[26] López-Escudero, F.J. and Blanco-López, M.A. (2005) Recovery of Young Olive Trees from Verticillium dahliae. European Journal of Plant Pathology, 113, 367-375. http://dx.doi.org/10.1007/s10658-005-3145-0

[27] Markakis, E.A, Tjamos, S.E., Antoniou, P.P., Roussos, P.A., Paplomatas, E.J. and Tjamos E.C. (2010) Phenolic Responses of Resistant and Susceptible Olive Cultivars Induced by Defoliating and Non-Defoliating Verticillium dahliae pathotypes. Plant Disease, 94, 1156-1162. http://dx.doi.org/10.1094/PDIS-94-9-1156

[28] López-Escudero, F.J., del Río Rincón, C., Caballero Reig J.M. and Blanco-López, M.A. (2007) Response of Olive Cultivars to Stem Puncture Inoculation with a Defoliating Pathotype of Verticillium dahliae. HortScience, 42, $294-298$.

[29] Prieto, P., Navarro-Raya, C., Valverde-Corredor, A., Amyotte, S.G., Dobinson, K.F. and Mercado-Blanco, J. (2009) Colonization Process of Olive Tissues by Verticillium dahliae and its in planta Interaction with the Biocontrol Root Endophyte Pseudomonas fluorescens PICF7. Microbial Biotechnology, 2, 499-511. http://dx.doi.org/10.1111/j.1751-7915.2009.00105.x

[30] Mercado-Blanco, J., Collado-Romero, M., Parrilla-Araujo, S., Rodríguez-Jurado, D. and Jiménez-Díaz, R.M. (2003) Quantitative Monitoring of Colonization of Olive Genotypes by Verticillium dahliae Pathotypes with Real-Time Polymerase Chain Reaction. Physiological and Molecular Plant Pathology, 63, 91-105. http://dx.doi.org/10.1016/j.pmpp.2003.10.001

[31] Karagiannidis, N., Bletsos. F. and Stavro Poulos, N. (2002) Effect of Verticillium wilt and Mycorrhiza (Glomus mosseae) on Root Colonization, Growth and Nutrient Uptake in Tomato and Eggplant Seedlings. Scientia Horticulturae, 94, 145-156. http://dx.doi.org/10.1016/S0304-4238(01)00336-3

[32] Goicoechea, N. (2006) Verticillium-Induced Wilt in Pepper: Physiological Disorders and Perspectives for Controlling the Disease. Plant Pathology Journal, 2, 258-265.

[33] Tjamos, E.C., Biris, D.A. and Paplomatas, E.J. (1991) Recovery of Olive Trees from Verticillium Wilt after Individual Application of Soil Solarization in Established Olive Orchards. Plant Disease, 75, 557-562. http://dx.doi.org/10.1094/PD-75-0557

[34] Collins, R.P. and Scheffer, R.P. (1958) Respiratory Responses and Systemic Effects in Fusarium-Infected Tomato Plants. Phytopathology, 48, 349-355.

[35] Talboys, P.W. (1968) Water Deficits in Vascular Diseases. In: Kozlowski, T.T., Ed., Water Deficits and Plant Growth, Vol. II, Academic Press, New York and London, 255-311. 